\title{
Genetic Recombination in Fused Spheroplasts of Providence alcalifaciens
}

\author{
By J. N. COETZEE, F. A. SIRGEL AND G. LECATSAS \\ Department of Microbiology, University of Pretoria, Republic of South Africa
}

(Received 20 December 1978)

\begin{abstract}
Spheroplasts of Providence alcalifaciens strain P29 auxotrophs were prepared by combined treatment with glycine and lysozyme-EDTA. About $15 \%$ of spheroplasts had areas of cytoplasmic membrane exposed where cell wall was absent. The spheroplasts of different auxotrophs were mixed pairwise and fusion was attempted with polyethylene glycol or nascent calcium phosphate. After spheroplasts had regenerated to bacterial forms selection was made for recombinants. Recombinants arose at frequencies of $3.8 \times 10^{-6}$ to $1.7 \times 10^{-7}$ per spheroplast initially present, by both methods of fusion. The frequency was strongly dependent on the number of chromosomal loci used in selection. The possible order of five loci was determined and this corresponded to that on the closely related Proteus mirabilis chromosome. Control experiments excluded possibilities of auxotrophic reversion, conjugation, transformation, transfection or transduction as explanations of the results. Analysis of prototrophic clones yielded stable prototrophs or mixtures of stable prototrophs and stable recombinants. Parental types were not encountered. Unselected markers segregated among recombinants. It was concluded that the formation of recombinant bacteria was due to spheroplast fusion and that only stable products of the very temporary heteroploid state were haploid recombinants. The low frequency of recombination was ascribed to the limited number of spheroplasts with areas of exposed cytoplasmic membrane.
\end{abstract}

\section{INTRODUCTION}

Fodor \& Alföldi (1976) and Schaeffer et al. (1976) described the production of genetic recombinants by fusion of protoplasts of Bacillus megaterium and Bacillus subtilis, respectively. Hopwood et al. (1977), Hopwood \& Wright (1978) and Baltz (1978) encountered frequent recombination accompanying protoplast fusion in Streptomyces spp.

There have been no reports regarding fusion of spheroplasts of Gram-negative bacteria. Lederberg \& St Clair (1958) recorded their failure to detect fusion of penicillin-induced 'protoplasts' of Escherichia coli. Various $\mathrm{F}^{-}$auxotrophic strains were used and criteria for positive results would have been the presence of clumping observed microscopically and ability to detect genetic recombination.

Van Rensburg (1969) demonstrated that lysozyme and EDTA treatment of a Providence alcalifaciens strain converted more than $99 \%$ of cells to spheroplasts. Similar treatment of a strain of Proteus mirabilis converted only $80 \%$ of cells.

We decided to attempt spheroplast fusion in Providence alcalifaciens, despite the fact that the chromosome of Proteus mirabilis strain PM5006 has been mapped (Coetzee, $1979 a, b$ ) and knowledge of marker location would have been useful (see Schaeffer et al., 1976; Hopwood \& Wright, 1978). There were three reasons for our choice. Firstly, in preliminary attempts to prepare spheroplasts by the combined method used (see Methods) the conversion frequency of Providence alcalifaciens strain P29 to spheroplasts was higher 
than that of Proteus mirabilis strain PM5006 and only spheroplasts of the former had areas of cytoplasmic membrane exposed. Secondly, Proteus mirabilis strain PM5006 is cryptically lysogenic for a generalized transducing phage (Krizsanovich, 1973) and this might have complicated the interpretation of fusion experiments. Providence alcalifaciens strain P29, despite extensive searches, has not been proved lysogenic (unpublished, and see Coetzee, 1963). Thirdly, due to the ability of Proteus mirabilis to swarm and the soft agar method used to plate spheroplasts (see Coetzee, 1972; Williams \& Schwarzhoff, 1978), difficulties in obtaining pure isolates of regenerated clones of bacteria were anticipated. Providence spp. may also spread or 'emanate' in soft agar, but at $37^{\circ} \mathrm{C}$ this tendency is absent in most strains (Coetzee \& De Klerk, 1964).

\section{METHODS}

Bacteria. These are listed in Table 1.

Bacteriophage techniques. These were according to Adams (1956).

Media and solutions. Nutrient broth was Bacto-Penassay Broth code 0243-01. MacConkey agar was from Difco. Minimal medium (MM) was that of Grabow \& Smit (1967). For auxotrophic strains, this medium was supplemented with amino acids, adenine or uracil (each at $30 \mu \mathrm{g} \mathrm{ml}^{-1}$ ) when necessary. Rich regeneration medium (RRM) was nutrient broth containing $0.01 \%(\mathrm{w} / \mathrm{v}$ ) casein hydrolysate (Oxoid), $0.5 \mathrm{M}$-sucrose, $20 \mathrm{mg}$ deoxyribonuclease $\mathrm{I} \mathrm{ml}^{-1}$ (Calbiochem) and $1.5 \%$ (w/v) Bacto-agar (Difco). RRM top-layer agar was similar but contained only $0.6 \%$ (w/v) Bacto-agar. MM, MacConkey agar and RRM contained $50 \mu \mathrm{g}$ nalidixic acid $\mathrm{ml}^{-1}$ to counter contamination. The lysozyme-EDTA spheroplasts were prepared in the sucrose/magnesium/maleate (SMM) buffer of Wyrick \& Rogers (1973) to which $20 \mu \mathrm{g}$ deoxyribonuclease I $\mathrm{ml}^{-1}$ had been added (SMMD). The glycine treatment was done in medium $\mathrm{G}$ which was nutrient broth containing $0.5 \mathrm{M}$-sucrose and $4 \%(\mathrm{w} / \mathrm{v})$ glycine; after autoclaving, $0.01 \mathrm{M}-\mathrm{MgCl}_{2}$ and $0.2 \%(\mathrm{w} / \mathrm{v}) \mathrm{MgSO}_{4}$. $7 \mathrm{H}_{2} \mathrm{O}$ were added as Millipore-filtered solutions. Tris buffer was $0.067 \mathrm{M}$ at $\mathrm{pH} 8$, and the EDTA solution was $4 \%(\mathrm{w} / \mathrm{v})$; both solutions were autoclaved. Lysozyme (Sigma) was prepared in Tris buffer at $3 \mathrm{mg} \mathrm{ml}^{-1}$. The polyethylene glycol (PEG) solution (Hopwood et al., 1977) consisted of $40 \%$ PEG (w/v) (mol. wt 6000) and $0.5 \mathrm{M}$-sucrose; after autoclaving a solution of dimethylsulphoxide was added to a concentration of $15 \%(\mathrm{w} / \mathrm{v})$. Incubation temperature was $37^{\circ} \mathrm{C}$.

Spheroplast preparation. A combined glycine and lysozyme-EDTA method was used. Bacteria grown overnight in $40 \mathrm{ml}$ aerated nutrient broth culture (titre, $2 \times 10^{9}$ to $3 \times 10^{9} \mathrm{ml}^{-1}$ ) were washed twice in Tris buffer and finally suspended in $1 \mathrm{ml} \mathrm{SMMD}$. Lysozyme $(0.4 \mathrm{ml})$ was added. After 3 min incubation, $0.05 \mathrm{ml}$ EDTA was blown in and incubation was continued for a further $18 \mathrm{~min}$. Then a further $3 \mathrm{ml}$ SMMD was added, the tube was centrifuged at $4000 \mathrm{~g}$ for $30 \mathrm{~min}$ and the deposit was suspended in $3 \mathrm{ml}$ SMMD. The contents of the tube were then added to $100 \mathrm{ml}$ medium $\mathrm{G}$ and incubated for $4 \mathrm{~h}$, by which time the culture had visibly increased in density. Then $100 \mathrm{ml}$ was centrifuged at $4000 \mathrm{~g}$ for $30 \mathrm{~min}$ and the deposit was suspended in $3 \mathrm{ml} \mathrm{SMMD}$. At this stage the suspension contained about $2 \times 10^{9}$ spheroplasts $\mathrm{ml}^{-1}$. Two ml of the suspension was used as a control and the remaining $1 \mathrm{ml}$ was mixed with $1 \mathrm{ml}$ of the similarly treated fusion partner. Tubes were finally centrifuged at $4000 \mathrm{~g}$ for $30 \mathrm{~min}$. All centrifugation was done at room temperature (about $25^{\circ} \mathrm{C}$ ).

Spheroplast lysate. This was made by suspending a pellet of spheroplasts in $3 \mathrm{ml}$ deionized water. After visual clearing of the suspensions the osmolarity was adjusted to that of medium $G$ with sucrose.

Enumeration of spheroplasts. This was done by counting in a haemocytometer under a phase-contrast microscope (Baltz, 1978; Okanishi et al., 1974). Colony formation by osmotically stable cells, contained in a spheroplast suspension, was determined by diluting the suspension in deionized water and plating on MacConkey agar. The difference between the latter count and the viable count of the bacterial suspension immediately prior to spheroplast preparation was used as an independent check on haemocytometer counts. These counts also enabled an estimate of the efficiency of spheroplast conversion.

Electron microscopy of spheroplasts. Spheroplasts were fixed by a modification of the method of Sagara et al. (1971). This involved treatment with $3 \%(\mathrm{v} / \mathrm{v})$ glutaraldehyde in phosphate buffer ( $\mathrm{pH} 7)$ containing $1 \mathrm{M}$-sucrose followed by post-fixation in $1 \%(\mathrm{w} / \mathrm{v}) \mathrm{OsO}_{4}$ for $4 \mathrm{~h}$; both steps were performed at $4{ }^{\circ} \mathrm{C}$. The fixed material was dehydrated in a series of graded ethanol dilutions and embedded in Epon 812. Sections were cut on a LKB ultramicrotome using glass knives and viewed in a Philips EM300 electron microscope at an instrumental magnification of 42000 and an accelerating voltage of $60 \mathrm{kV}$.

Spheroplast fusion. The two methods of Fodor \& Alföldi (1976) were used. (1) Calcium phosphate treatment. The spheroplast deposit after the final centrifugation was suspended in $2 \mathrm{ml} \mathrm{SMMD.} \mathrm{To} \mathrm{this} \mathrm{was}$ added first $0.1 \mathrm{ml} 0.02 \mathrm{M}-\mathrm{KH}_{2} \mathrm{PO}_{4}$ and then $0.1 \mathrm{ml} 1.0 \mathrm{M}-\mathrm{CaCl}_{2}$. After $1 \mathrm{~min}$ of gentle shaking the spheroplasts were plated. (2) PEG treatment. The final centrifuged pellet was suspended in $0 \cdot 2 \mathrm{ml} \mathrm{SMMD} \mathrm{and}$ 


\section{Table 1. Strains of Providence alcalifaciens}

Strain

P29 nal-1
Relevant properties

P29 is the laboratory designation of NCTC 9211. Non-lysogenic despite many attempts to prove to the contrary. Susceptible to many Providence phages including the generalized transducing phage PL25. Spontaneous mutant resistant to at least $100 \mu \mathrm{g}$ nalidixic acid $\mathrm{ml}^{-1}$

AK100 trp-10 auxotroph of P29 nal-1 obtained by NTG treatment

AK115

ilv-2 auxotroph of P29 nal-1 obtained by NTG treatment

AK200

ade-1 his-22 auxotroph of P29 nal-1 obtained by successive NTG treatments

AK227 ura-4 met-3 auxotroph of P29 nal-1 obtained by successive NTG treatments

NTG, $N$-Methyl- $N^{\prime}$-nitro- $N$-nitrosoguanidine.

\author{
Reference \\ Coetzee (1963, 1975, \\ and unpublished); \\ Coetzee et al. (1966)
}

A. Kruger \& J. N. Coetzee (unpublished)

A. Kruger \& J. N. Coetzee (unpublished)

A. Kruger \& J. N. Coetzee (unpublished)

A. Kruger \& J. N.

Coetzee (unpublished)

$1.8 \mathrm{ml}$ PEG was added. After gentle agitation for $1 \mathrm{~min}$ the spheroplasts were plated. All the above operations were done at room temperature (about $25^{\circ} \mathrm{C}$ ).

Plating of fusion mixtures and subsequent procedures. Suspensions were plated by transfer of $0 \cdot 1 \mathrm{ml}$ into $2.5 \mathrm{ml}$ molten top-layer RRM agar maintained at $45^{\circ} \mathrm{C}$ and poured over the surface of RRM plates. To determine regeneration frequencies of spheroplasts in fusion mixtures, further dilutions in SMMD were made and plated as above. Plates were incubated for $48 \mathrm{~h}$. Bacterial colonies on the most heavily inoculated plates were only then subjected to selection by replication to MM or supplemented MM, while regenerated spheroplasts were counted on the more sparsely seeded RRM. Regeneration efficiency was expressed as the ratio of the number of colonies appearing on these plates to the number of spheroplasts plated.

Control experiments. To exclude possibilities of transformation or transfection, deoxyribonuclease I was added after spheroplast formation and was present in fluid media subsequently used as well as in RRM. Supernatants of samples of overnight broth cultures of strains as well as final spheroplasts suspensions, immediately prior to addition of fusion agents, were tested for lytic phage by plating on P29 nal-1. Experiments were also done with spheroplasts derived from each parent singly, with mixtures of parental bacteria (instead of their spheroplasts) and with mixtures of one of the parental bacteria, or spheroplasts derived from it, and a spheroplast lysate of the fusion partner. In other experiments, only the fusion agents were omitted from the experimental protocol.

Analysis of primary prototroph clones. Colonies arising on primary MM replica plates were picked off into individual tubes containing $10 \mathrm{ml}$ nutrient broth and grown overnight. Dilutions were then made and plated on MacConkey agar to yield about 100 colonies per plate after incubation. These plates were then replicated to MM or supplemented MM. Samples of clones arising on the latter secondary replication media were again tested by the same procedure.

Segregation of unselected markers among recombinants. Colonies obtained on doubly supplemented MM primary replica plates were patched on the same medium. After overnight incubation, these plates were replicated to $\mathrm{MM}$ and $\mathrm{MM}$ supplemented with either or both of the two growth factors.

\section{RESULTS}

\section{Properties of spheroplasts}

Microscopic appearance. Examination in a phase-contrast microscope showed that more than $99 \%$ of organisms were converted to spherical forms as a result of the glycine and lysozyme-EDTA treatment. Electron microscope examination (Figs 1 to 4) revealed that the outer trilaminar component of the cell wall was broken in about $15 \%$ of spheroplasts. These breaks exposed areas of underlying cytoplasmic membrane. Many cell wall vesicles (Hofschneider \& Martin, 1968) were also present.

Osmotic sensitivity. Suspension of a pellet of spheroplasts in deionized water caused rapid lysis of the spheroplasts accompanied by visual clearing of the suspension. This sensitivity, together with the special morphology and retention of some cell wall material, fits a definition of a spheroplast (McQuillen, 1960). 

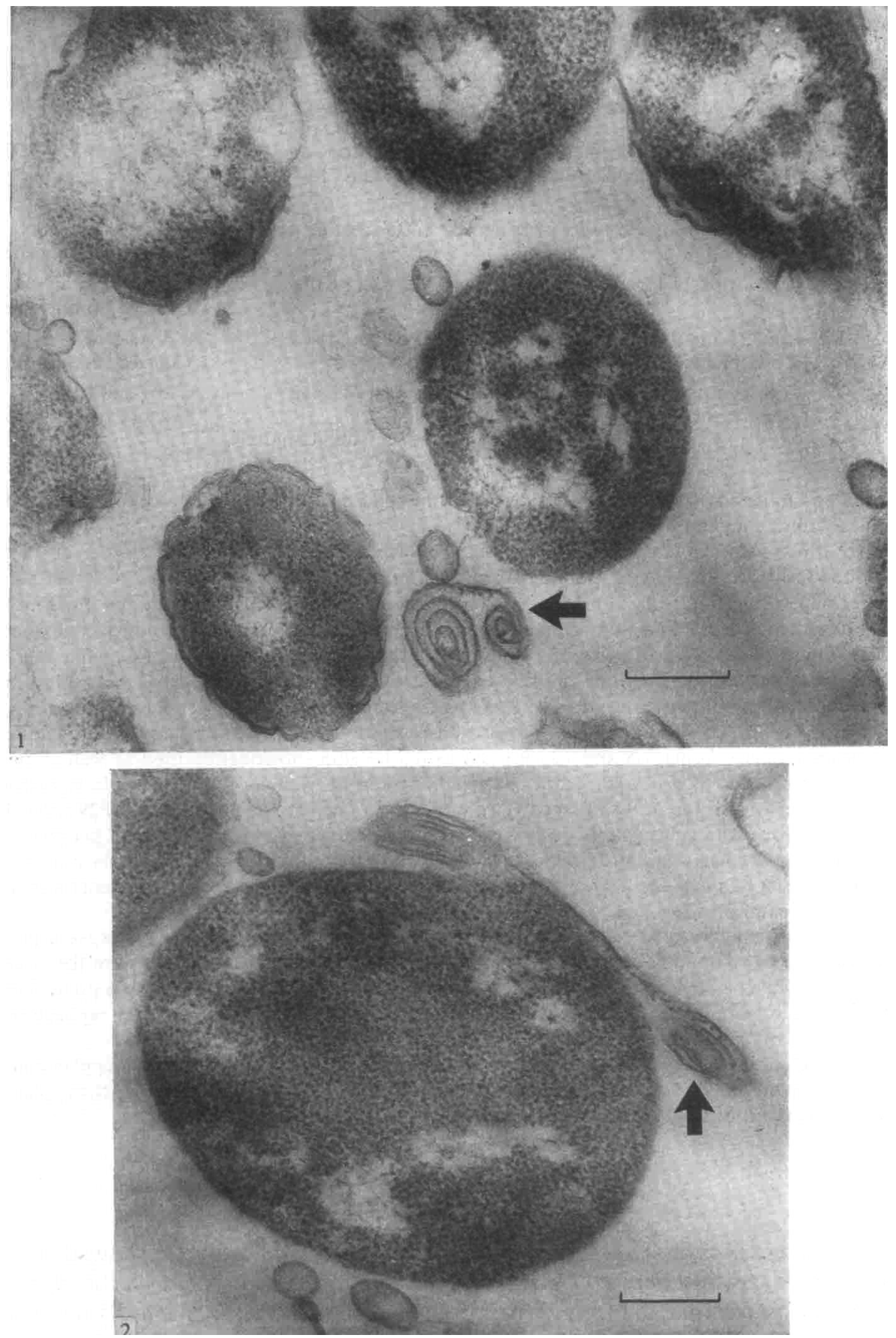

Figs 1 to 4. Thin sections of spheroplasts of Providence alcalifaciens strain AK200 produced by combined glycine and lysozyme-EDTA treatment. Arrows indicate whorled cell wall material. The underlying cytoplasmic membrane is then exposed. Small vesicles, evident in all the photomicrographs, represent wall material in different section planes. Figure 1 shows a spheroplast devoid of cell wall, surrounded by others with possibly intact cell walls. Bar markers represent $100 \mathrm{~nm}$. 

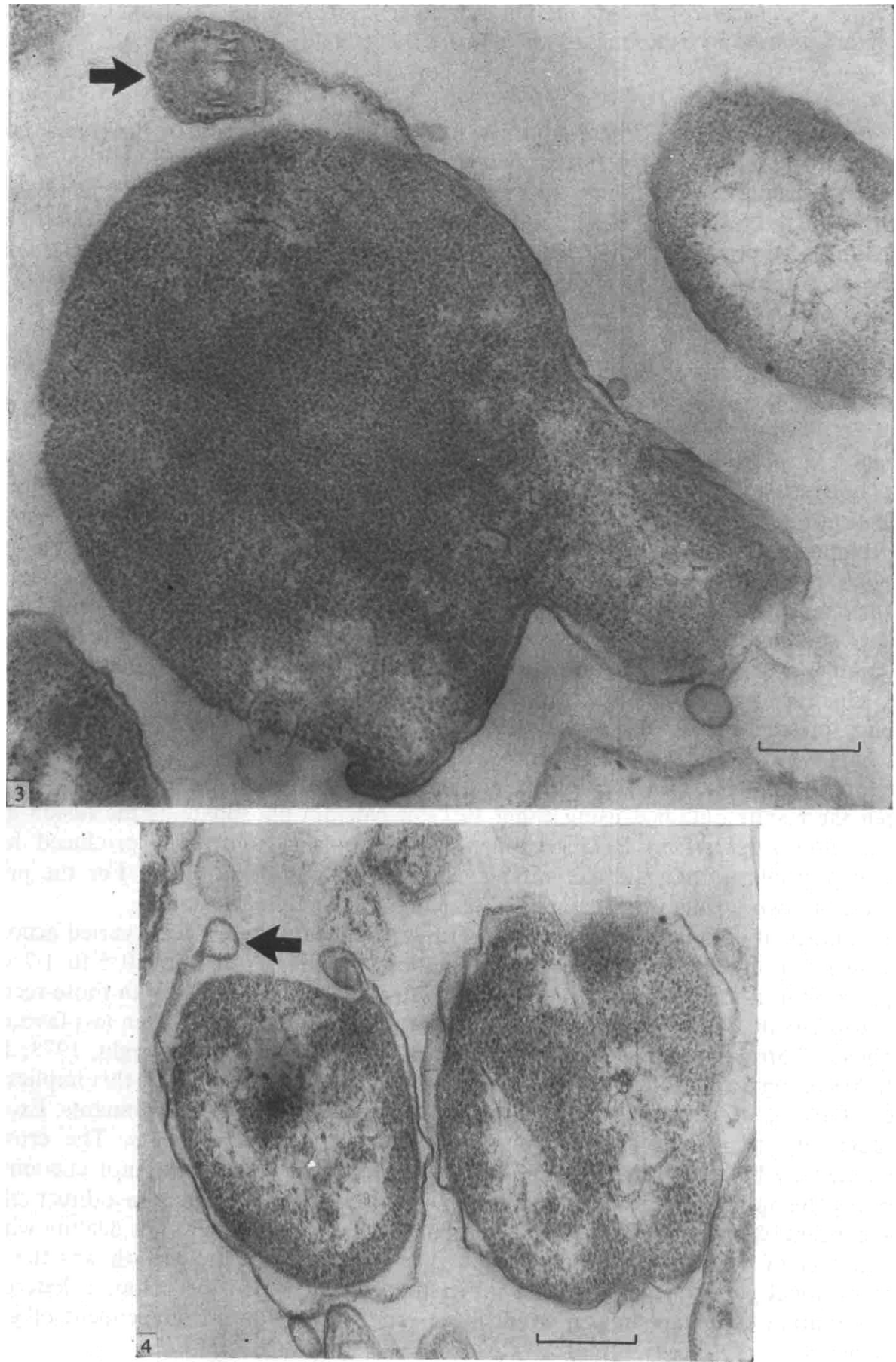
Efficiency of spheroplast formation. This varied from 0.98 to 0.99 and the concentration of spheroplasts used in experiments was usually $2 \times 10^{9} \mathrm{ml}^{-1}$.

\section{Spheroplast fusion}

Microscopic appearance. Phase-contrast microscopy of spheroplast mixtures before centrifugation and addition of fusion agents revealed homogeneous suspensions of welldispersed spheroplasts. Examination of final mixtures after centrifugation and treatment with either of the fusion agents showed many clumps consisting of 2 to 10 spheroplasts. Aggregation does not necessarily imply fusion (Schaeffer et al., 1976) and an estimate of the number of genomes possibly contained in one fused cellular unit is not available (see Hopwood \& Wright, 1978).

Regeneration efficiency of spheroplasts in fusion mixtures. This varied from 0.01 to 0.3 but in most experiments a value of about $0 \cdot 1$ was obtained. Due to aggregation produced by the fusion agents, these figures are lower than would be expected from untreated spheroplasts (see Baltz, 1978).

Genetic evidence of spheroplast fusion. Plaque-forming phage was not detected in supernatants of overnight broth cultures or in spheroplast preparations. Colonies which appeared on selection replica plates arose on the master RRM plates in the continued presence of deoxyribonuclease. Control experiments set up with the bacterial phase of single or double auxotroph pairs with or without spheroplast lysates of one of the partners, often had 1 to 10 clones on MM or singly supplemented MM replica plates, respectively (not shown). This corresponded to maximum reversion frequencies of about $5 \times 10^{-8}$ per locus. In contrast, control experiments with single spheroplast suspensions never had growth on replica plates. This may be due to the high efficiency of spheroplast formation coupled to a low frequency of spheroplast regeneration (see above). Clones arose on test selective replica plates only when use of a fusion agent was included (not shown) and this implicated the action of fusion agents in the results obtained. No consistent difference was detected between the results obtained using either PEG or calcium phosphate as the fusion agent. With Bacillus megaterium, PEG treatment of protoplasts sometimes produced higher yields of protoplasts than did the latter agent (Fodor \& Alföldi, 1976). For the present purposes, the two agents will be regarded as having identical effects.

The number of colonies which arose on primary replica plates of tests varied according to the selection applied (Table 2). Recombination frequencies of $3.8 \times 10^{-6}$ to $1.7 \times 10^{-7}$ per spheroplast in mixtures prior to addition of fusion agent are lower than those recorded for protoplasts of Bacillus subtilis (Schaeffer et al., 1976) and compare even less favourably with those of Streptomyces spp. (Hopwood et al., 1977; Hopwood \& Wright, 1978; Baltz, 1978). Assuming a spheroplast regeneration frequency of $0 \cdot 1$ (see above), this implies that, at most, $0.003 \%$ of spheroplasts which regenerated a cell wall were recombinants. Excellent reproducibility of results was demonstrated in numerous experiments. The crowding effect noted by Schaeffer et al. (1976) and Hopwood et al. (1977) was not encountered. Invariably the number of recombinants which arose on a replica plate bore a direct relation to the concentration of the fusion mixture plated. Obviously we were not dealing with the total number of heteroploids produced and this suggested that the growth was the result of post-fusional genetic recombination rather than repeated division of initial heteroploid cells, as mutual complementation would have rendered the latter independent of growth supplements.

Analysis of primary colonies. Fifty colonies, each arising on the primary MM replica plates of fusion crosses AK200 $\times$ AK 227 or AK $200 \times$ AK100 (Table 2) were examined. Two types of clones were encountered (not shown). The first (and most frequent) consisted of mixed populations of prototrophs and one, or very rarely, two other recombinants. The second type of clone only yielded prototrophs. Parental types were never isolated. These types of prototroph clones were found in both the above fusion experiments in about equal 
Table 2. Analysis of recombinant colonies which arose on primary selective replica plates in spheroplast fusion experiments

Fusion experiments were done as described in Methods. The concentration of mixed spheroplasts, before fusion, was $2 \times 10^{9} \mathrm{ml}^{-1}$. Parental spheroplasts, singly, produced no colonies on replica plates of control experiments. For results of other control experiments, see text.

\begin{tabular}{|c|c|c|c|c|}
\hline Cross & $\begin{array}{l}\text { Supplementation of } \mathrm{MM} \\
\text { replica plates }\end{array}$ & No. of clones & $\begin{array}{c}10^{6} \times \\
\text { Recombination } \\
\text { frequency }\end{array}$ & $\begin{array}{l}\text { Minimum no. } \\
\text { of crossovers } \\
\text { required }\end{array}$ \\
\hline AK $200 \times$ AK 227 & $\begin{array}{l}\text { None } \\
\text { Adenine } \\
\text { Histidine } \\
\text { Uracil } \\
\text { Methionine } \\
\text { Adenine, methionine } \\
\text { Uracil, histidine }\end{array}$ & $\begin{array}{r}34 \\
338 \\
765 \\
727 \\
359 \\
710 \\
625\end{array}$ & $\begin{array}{l}0 \cdot 17 \\
1 \cdot 7 \\
3 \cdot 8 \\
3 \cdot 6 \\
1 \cdot 8 \\
3 \cdot 5 \\
3 \cdot 1\end{array}$ & $\begin{array}{l}2 \text { or } 4 \dagger \\
2 \text { or } 4 \dagger \\
2 \dagger \\
2 \text { or } 4 \dagger \\
2 \text { or } 4 \dagger \\
2 \dagger \\
2 \dagger\end{array}$ \\
\hline $\mathrm{AK} 100 \times \mathrm{AK} 200$ & $\begin{array}{l}\text { None } \\
\text { Adenine } \\
\text { Histidine }\end{array}$ & $\begin{array}{l}303 \\
701 \\
748\end{array}$ & $\begin{array}{l}1 \cdot 5 \\
3 \cdot 5 \\
3 \cdot 7\end{array}$ & $\begin{array}{l}2 \text { or } 4 \ddagger \\
2 \div \\
2 \div\end{array}$ \\
\hline AK $100 \times$ AK 115 & None & 690 & $3 \cdot 5$ & 2 \\
\hline
\end{tabular}

*Per spheroplast in mixture immediately prior to fusion.

$\uparrow$ Based on locus sequences ade his ura met, ade ura his met or ade ura met his.

$\ddagger$ Based on locus sequences ade trp his or trp ade his.

Table 3. Segregation of unselected markers among recombinants from a AK200 $\times$ AK227 fusion experiment

Colonies obtained on MM supplemented with two of the four growth factors, were patched on the same medium. After overnight incubation, these plates were replicated on $\mathrm{MM}$ and on $\mathrm{MM}$ containing either growth factor or both.

\begin{tabular}{|c|c|c|c|c|}
\hline \multirow[b]{2}{*}{$\begin{array}{l}\text { Unselected } \\
\text { markers }\end{array}$} & \multicolumn{4}{|c|}{ Percentage of colonies having indicated constitution } \\
\hline & $\begin{array}{c}\text { AK200 } \\
\text { parental type } \\
(-/+)\end{array}$ & $\begin{array}{c}\text { AK227 } \\
\text { parental type } \\
(+/-)\end{array}$ & $\begin{array}{c}\text { Recombinant } \\
(+/+)\end{array}$ & $\begin{array}{c}\text { Recombinant } \\
(-1-)\end{array}$ \\
\hline $\begin{array}{l}\text { ade/met } \\
\text { his/ura }\end{array}$ & $\begin{array}{l}15 \\
42\end{array}$ & $\begin{array}{l}25 \\
35\end{array}$ & $\begin{array}{r}25 \\
8\end{array}$ & $\begin{array}{l}35 \\
15\end{array}$ \\
\hline
\end{tabular}

numbers. A limited amount of testing (see Methods) of the secondary colonies arising from the above primary clones revealed them to be stable (see Schaeffer et al., 1976).

Segregation of unselected markers. The requirements of partial prototrophs for the two growth factors which were present during selection (Table 2, lines 6,7 ) were determined by replica-plating (Table 3). The two parental and two recombinant types were encountered in both experiments. The results of these experiments independently support those above which suggest that the fusion-induced recombinants are haploid.

\section{DISCUSSION}

Control experiments ruled out possibilities of auxotroph reversion, conjugation, transformation, transfection or transduction as explanations of the results. The fact that colonies arose on test plates only after treatment with protoplast fusion agents implicated spheroplast fusion as the cause of the results obtained. The effect of centrifugation in promoting protoplast adhesion (Ferenczy et al., 1976; Fodor \& Alföldi, 1976) was not investigated independently although centrifugation of mixed spheroplasts formed part of the experimental protocol.

The strategy employed in making spheroplasts was to attack the peptidoglycan layer of the cell wall at two different sites. Glycine apparently acts by interfering with cross-linking 
of the muramic acid peptide molecules (Strominger, 1968), while lysozyme destroys certain glycoside linkages between the amino sugars (Rogers \& Perkins, 1968) once the former have been exposed, in Gram-negative bacteria, by the chelating action of EDTA (Repaske, 1956, 1958). Unlike lysozyme-EDTA treatment or glycine treatment, alone, which convert Providence cells to spheroplasts possessing an entire outer integument (Van Rensburg, 1969), their combined action often resulted in rupture of this structure with exposure of the underlying cytoplasmic membrane (Figs 1 to 4). The combined action of glycine and lysozyme without EDTA has been used by Sagara et al. (1971) and Baltz (1978) for the formation of protoplasts in Gram-positive Streptomyces spp. Birdsell \& Cota-Robles (1967) and Costerton et al. (1967) produced spheroplasts of Escherichia coli and a marine pseudomonad, respectively, by using only lysozyme-EDTA treatment. These spheroplasts had large breaks in the outer cell wall integument.

If the fusion of spheroplasts demonstrated here took place in the exposed areas of cytoplasmic membrane, then the limited areas available would result in frequencies of spheroplast recombination lower than those encountered with protoplast fusion. Pontecorvo et al. (1977) have suggested that in human fibroblasts, PEG-mediated fusion occurs in very restricted areas at or near the tips of the filamentous processes of these cells.

Quite apart from the particular method used for spheroplast preparation or the fusion techniques employed, recombinant recovery is also (and finally) dependent on the regeneration of spheroplasts to cells (Baltz, 1978). As selection was only applied after regeneration, the constraint of only complementing (fused) spheroplasts being able to regenerate cell wall was removed (see Fodor \& Alföldi, 1976). The estimated frequency of spheroplast regeneration after fusion treatment (about $0 \cdot 1$ ) was of the same order as recorded for Bacillus spp. protoplasts (Fodor \& Alföldi, 1976; Schaeffer et al., 1976) but decidedly lower than that recorded for Streptomyces spp. by Okanishi et al. (1974), Hopwood et al. (1977) and Baltz (1978). Toxicity of one of the treatments could be involved (see Baltz, 1978) but frequencies presented here are lower than would be expected as spheroplasts and not protoplasts were used. The former possess remnants of cell wall which could act as primers for new cell wall elements during the regeneration process (Hofschneider \& Martin, 1968; Landman, 1968).

Analysis of primary prototrophic clones suggested that, in all cases, the initial heteroploid phase was soon succeeded by one or more haploid recombinants. Fodor \& Alföldi (1976) found a class of primary prototrophic clones of Bacillus subtilis which gave rise to mixed populations in which the prototrophic elements were unstable, but we found no such class.

Prototroph recombinants were more frequent in double $\times$ single auxotrophic spheroplast fusions, and in single $\times$ single auxotroph spheroplast matings, than in fusions where both partners were double auxotrophs (Table 2). This was expected since in the first two fusion types mentioned two crossover events (depending on the relationship of the chromosomal loci to one another) would restore one of the parental genomes to prototrophy, while in the latter case four crossovers would be required. The locus order ade-1 ura-4 his-22 met-3 best fits the results of the first cross listed in Table 2 . Similarly the order derived from the second cross could be ade-1 trp-10 his-22. Although the particular genes corresponding to the above loci have not been identified, the locus order corresponds to that of the Proteus mirabilis chromosome (Coetzee, 1979 $a, b$ ). Providence and Proteus strains are closely related (Coetzee, 1972). If this comparison is valid, some of the recombinants isolated here involved regions separated by about half the length of the chromosome. This indicates extensive initial diploidy. Fusion crosses may be useful in generating many combinations of parental genes (see Hopwood \& Wright, 1978).

Although conventional genetic analysis of Providence alcalifaciens is proceeding by means of $\mathbf{R}$ plasmids capable of chromosome mobilization (A. Kruger \& J. N. Coetzee, unpublished), the work presented here resembles that of Fodor \& Alföldi (1976) for Bacillus megaterium in that it precedes reports of chromosomal recombination brought about by conjugation. 
The prime advantage of genetic recombination through spheroplast fusion is that it opens the way for genetic analysis in organisms lacking sex factors. Another advantage is that counterselection for one of the parents is not required. A third benefit is the general loosening of linkage (Hopwood et al., 1977) resulting from the temporary (at least) confrontation and complementation, in the same cell, of possibly entire parental genomes. The use of this technique to promote interspecies recombination is being studied.

J. N. C. is in receipt of grants from the South African Medical Research Council.

\section{REFERENCES}

ADAMs, M. H. (1956). Methods of study of bacterial viruses. Methods in Medical Research 2, 1-73.

BALTZ, R. H. (1978). Genetic recombination in Streptomyces fradiae by protoplast fusion and cell regeneration. Journal of General Microbiology 107, 93-102.

Birdsell, D. C. \& Cota-Robles, E. H. (1967). Production and ultrastructure of lysozyme and ethylenediaminetetraacetate-lysozyme spheroplasts of Escherichia coli. Journal of Bacteriology 93, 427437.

Coetzee, J. N. (1963). Lysogeny in Providence strains and the host-range of Providence bacteriophages. Nature, London 197, 515-516.

Coetzee, J. N. (1972). Genetics of the Proteus group. Annual Review of Microbiology 26, 23-54.

Coetzee, J. N. (1975). Specialized transduction of kanamycin resistance in a Providence strain. Journal of General Microbiology 88, 307-316.

Coetzee, J. N. (1979a). Genetic circularity of the Proteus mirabilis linkage map. Journal of General Microbiology 119, 171-176.

Coetzee, J. N. $(1979 b)$. Patterns of mobilization of the Proteus mirabilis chromosome by $\mathbf{R}$ plasmids. Journal of General Microbiology 111, 243-251.

CoetzeE, J. N. \& DE KLERK, H. C. (1964). Effect of temperature on flagellation, motility and swarming of Proteus. Nature, London, 202, 211-212.

Coetzee, J. N., Smit, J. A. \& Prozesky, O. W. (1966). Properties of Providence and Proteus morganii transducing phages. Journal of General Microbiology 44, 167-176.

Costerton, J. W., Forsberg, C., Matula, T. I., Buckmire, F. L. A. \& MacLeod, R. A. (1967). Nutrition and metabolism of marine bacteria. XVI. Formation of protoplasts, spheroplasts, and related forms from a gram-negative marine bacterium. Journal of Bacteriology 94, 176-177.

Ferenczy, L., KeVei, F. \& Szegedi, M. (1976). Fusion of fungal protoplasts induced by polyethylene glycol. In Microbial and Plant Protoplasts, pp. 177-188. Edited by J. F. Perberdy, A. H. Rose, H. J. Rogers \& E. C. Cocking. London: Academic Press.

FoDOR, K. \& AlFöldI, L. (1976). Fusion of protoplasts of Bacillus megaterium. Proceedings of the National Academy of Sciences of the United States of America 73, 2147-2150.

Grabow, W. O. K. \& SmIt, J. A. (1967). Methionine synthesis in Proteus mirabilis. Journal of General Microbiology 46, 47-57.

HofsChNEIDER, P. H. \& MarTin, H. H. (1968).
Diversity of surface layers in L-forms of Proteus mirabilis. Journal of General Microbiology 51, 23-33.

Hopwood, D. A. \& WRight, H. M. (1978). Bacterial protoplast fusion. Molecular and General Genetics 162, 307-317.

Hopwood, D. A., WRIGHT, H. M., BIBB, M. J. \& COHEN, S. N. (1977). Genetic recombination through protoplast fusion in Streptomyces. Nature, London 268, 171-174.

Krizsanovich, K. (1973). Cryptic lysogeny in Proteus mirabilis. Journal of General Virology 19, 311-320.

LANDMAN, O. E. (1968). Protoplasts, spheroplasts and $\mathbf{L}$-forms viewed as a genetic system. In Microbial Protoplasts, Spheroplasts and L-forms, pp. 319-332. Edited by L. B. Guze. Baltimore: Williams \& Wilkins.

Lederberg, J. \& St Clair, J. (1958). Protoplasts and L-type growth of Escherichia coli. Journal of Bacteriology 75, 143-160.

MCQUillen, K. (1960). Bacterial protoplasts. In The Bacteria, pp. 249-359. Edited by I. C. Gunsalus \& R. Y. Stanier. London: Academic Press.

OKanishi, M., SUZUKI, K. \& UMEZawa, H. (1974). Formation and reversion of Streptomycete protoplasts: cultural condition and morphological study. Journal of General Microbiology 80, 389-400.

Pontecorvo, G., Riddle, P. N. \& Hales, A. (1977). Time and mode of fusion of human fibroblasts treated with polyethylene glycol (PEG). Nature, London 265, 257-258.

REPASKE, R. (1956). Lysis of gram-negative bacteria by lysozyme. Biochimica et biophysica acta 22, 189-191.

REPASKE, R. (1958). Lysis of gram-negative organisms and the role of Versene. Biochimica et biophysica acta 30, 225-232.

Rogers, H. J. \& Perkins, H. R. (1968). The Mucopeptides. In Cell Walls and Membranes, pp. 231258. Edited by C. Long. London: E. \& F. N. Spon.

Sagara, Y., Fukui, K., Ota, F., Yohida, N., Kashiyama, T. \& Fujimoto, M. (1971). Rapid formation of protoplasts of Streptomyces griseoflavus and their fine structure. Japanese Journal of Microbiology 15, 73-84.

SCHAEFFER, P., CAMI, B. \& HotchKiss, R. D. (1976). Fusion of bacterial protoplasts. Proceedings of the National Academy of Sciences of the United States of America 73, 2151-2155. 
Strominger, J. L. (1968). Enzymatic reactions in bacterial cell wall synthesis sensitive to penicillins and other antibacterial substances. In Microbial Protoplasts, Spheroplasts and L-forms, pp. 55-61. Edited by L. B. Guze. Baltimore: Williams \& Wilkins.

Van Rensburg, A. J. (1969). Properties of Proteus mirabilis and Providence spheroplasts. Journal of General Microbiology 56, 257-264.
Williams, F. D. \& Schwarzhoff, R. H. (1978). Nature of the swarming phenomenon in Proteus. Annual Review of Microbiology 32, 101-122.

WYRICK, P. B. \& Rogers, H. J. (1973). Isolation and characterization of cell wall-defective variants of Bacillus subtilis and Bacillus licheniformis. Journal of Bacteriology 116, 456-465. 